\title{
A Study of Policy for Providing Feedback to Students on College English
}

\author{
Liping Chen \\ School of Foreign Languages, Yunnan Agricultural University \\ Yunnan Province, Kunming 65020, China \\ Tel: 86-871-666-1791Ｅ-mail:annaclp@sina.com
}

The research is supported by Yunnan Education Science "Eleven Five” Layout project (GY080024).

\begin{abstract}
Feedback is central to the development of effective learning in college English. This article presents a study on feedback to students on college English. The purpose of providing feedback to the students is to help teachers and students to identify their strengths and weaknesses. The author offers different kinds of feedback in her teaching. There is no such thing as perfect feedback; different types of assessment require different sorts of comments. But good feedback should encourage the students' deep approach to learning.
\end{abstract}

Keywords: Formative feedback, Effective feedback, Summative feedback, Deep approach to learning

\section{Introduction}

Feedback is an essential component in the learning and explains the gaps in knowledge and understanding, providing for reflection and development. Feedback at its best is pivotal in the learning and assessment process. (Orrell, 2006).

"Feedback may operate both to improve learning of individual students, and to improve teaching." (Biggs, 2003 p141).

'The purpose of providing feedback to the students is to help teachers and students to identify their strengths and weaknesses as they learn and to improve those areas. The feedback should not merely be to make things better next time. Giving feedback can itself be turned into part of learning experience.' (Race, 2007, p192-204). So providing feedback to students is one of the most important aspects of teaching.

Good feedback comprises not just commentary about what has been done, but suggests for what has been done next. (Brown, 2007) Good feedback can encourage and motivate students, clear up misunderstandings or confusion and improve the students' performance. Good feedback is recognized as being prompt, is related to the learning outcomes of the assignment, individualized to the student, but manageable for the lecturer. (Race, 2001). However on writing effective feedback academics complain that many students are poor at using feedback. Often they are more interested in their grade or marks and sometimes they pay little attention to read what we have written. When receiving feedback, they frequently fail to remember what is said to them, except for when their views of how they have done are confirmed. So a study of policy for providing feedback to students on college English is useful. How can we get students to make best use of feedback? We should find ways to help students make good use of the hard work we put into giving them feedback.

We considered Biggs(2003) SOLO taxonomy and assessing for learning quality II practice as an assessment guide, particularly the relational thinking as we were looking for the students to compare, contrast and analyses within their work. It is important and useful to analysis a range of methods for providing feedback to our students. Reflect upon our own experiences of both providing and receiving feedback and evaluate the importance of these experiences of feedback within our own teaching.

\section{The feedback analysis}

\subsection{Why provide feedback?}

“...it makes sense to ensure that a lot of feedback is given to students very early on in the process when they are being coached to perform well; as they progress towards the end of a module, when they are well aware of what is required of them, they need less feedback." (Brown and Knight 1994, p.99)

\subsection{Why give feedback?}

"It is impossible to overstate the role of effective comments on students' progress in any discussion of effective teaching and assessment." (Ramsden, 2003, p.187)

\subsection{Purposes of feedback}

Justify the mark or grade awarded - to various audiences

-Show the student where their strengths and weaknesses lie 
-Identify a profile of attainment against the criteria established for the assessment

-Identify how the student might achieve a heightened performance

$\cdot$ Help the student identify where they might focus their efforts for future development and assessment

-To identify where they might get further help

-To promote learning and facilitate improvement by encouraging students to reflect upon their performance

-Motivate and reward students

-To aid staff in monitoring the assessment ---validity, reliability

-Provide information to aid the external monitoring process

There is no such thing as perfect feedback, different types of assessment require different sorts of comments. However, as I think feedback should

be positive;

give 2 or 3 powerful pieces of advice as the bulk of the comment;

avoid insisting that your view is necessarily the right one;

-mark points of error in the text, including where assertion is made without evidence;

advice on structure and organization should be freely given;

·check how you think the advice given is going to help the learner do better next time. (Brown and Knight 1994, p.113).

Different types of feedback seem to encourage the students' surface or deep approaches to learning. The teacher should give feedback to make the students deep approach to learning. So students may have positive feelings: interest, a sense of importance, challenge, even of exhilaration. As a teacher, I give students effective feedback, which should be fast, focused, relevant to assessment criteria, developmental and personal to the student.

During my teaching, I have had to provide formative and summative feedback, depending on different kinds of assignments and examinations. Especially I pay more attention to the formative feedback, for it helps the students identify 'gaps' in their knowledge, understanding and skills set.

\section{Formative feedback}

Formative feedback is principally a mean by which tutors can let the students know how learning is proceeding. It refers to constructive feedback offered to students in an attempt to develop their learning language. Formative feedback and link to deep learning (feedforward) (Higgins, Hartley and Skelton 2002 in Carless), it checks ongoing understanding and instructs the students about their error, leading to better understanding in future. The important problem is how I can get students to make use of formative feedback. So different kinds of formative feedback is very useful to the students. The following is the formative feedback I have provided.

\subsection{Timely feedback:}

'Students generally find timely feedback far more useful than delayed comments' (Ramsden, p.88).Students need appropriate feedback on performance to benefit from courses. Students need help in assessing existing knowledge and competence. So in class students need timely feedback to reflect on what they have learned, what they still need to know, and how to assess themselves.

\subsubsection{Face to face feedback}

In listening course, I often give them timely feedback. I give praise'good, very good, excellent 'for their correct answers or point out the errors, saying 'you may listen to the passage again and try to find the right answer', together with brief explanations--- you should pay attention to the number, which you must calculate, and recommend them to write down some key words while listening.

I also give face to face feedback to a small group of students or to an individual. Face to face communication made the feedback more clear and the response from the student made reflect my teaching.

\subsubsection{Verbal feedback}

For the assignment as oral practice, presentation and retell, I usually gave the feedback verbally in class, such as 'Well done. Congratulations. You summarize the text better than last time; I hope to see your perfect performance next time.' Sometime I do interview, one-to-one; one-to-group in class; but after class I may be do lunch \& discussion to exchange the views between the students and me.

\subsubsection{One- to- one feedback}

For some errors in the assignment, I provide one to one formative feedback as shown in the following: 
Tutorial record: Formative feedback to students

Subject: New Horizon College English Book I

Students name: Gao Hua

Tutor: Chen Liping

Module Title: Composition--- View on Generation Gap

Key point for discussion:

Paragraph Topic Sentences about the composition.

- Generation gap exists in our life

- People have different opinions on the reason why generation gap comes into being.

- Both generations should be responsible for solving the problem.

\section{Agreed target and action:}

Write about 150 words composition next week.

\section{Additional Staff Comments:}

Grasp the hints of the composition.

Staff Signature: Chen Liping Student Signature: Gao Hua

Date: $\quad 25 / 10 / 2007$

Formative feedback of one to one tutorials is to encourage the student with their work and provide agreed targets and actions. Askew and Lodge(2000) identify three accounts of feedback, the dominant where the teacher help the student to learn, the constructivist view to connect old and new experiences where teacher and learner can make a dialogue, the feedback is more descriptive. The discussions between the teacher and the students are constructivist in the approach, reflecting back on previous sessions and connecting the old and new experiences.

\subsection{Useful feedback: A marks system, a correction code or written comments}

In my teaching I use a marks system to define the grading categories, such as A ( + +, A, A_), B ( $\left.\mathrm{B}+, \mathrm{B}, \mathrm{B} \_\right), \mathrm{C}$ and D for students homework, dictation and translation.

For written compositions, I usually make a correction code on the writing that guides and encourage students to think about their mistakes. Here is an example: $\mathrm{T}=$ wrong tense, $\mathrm{G}=$ wrong grammar, $?=\mathrm{I}$ don't understand, $\wedge=$ missing words. Sometimes I write some comments that should be a better balance between positive and critical feedback.

For example, I write "'You have written a well-structured and clearly argued essay. Furthermore, you have used a lot of these complex sentences and high-level grammar. Unfortunately, the main problem is that a typical example of Chinglish. You have thought about what you want to say in Chinese and then translate it literally using the 虽然(shui ran).......但是(dan shi)construction. The problem with using this construction is that it cannot be literally translated into English. We only use 'although' in English, not 'although ... but'.

Then the students try to correct themselves. After that I will give them model writing. Marking is time consuming so rapid return of scripts is not always possible. I often find that I correct the same mistakes and writing the same comments many times. Providing rapid, effective feedback to students is important, allowing engagement which makes easy or less difficult learning and improves subsequent performance. Giving students detailed and developmental formative feedback is very useful for our students.

Ramsden (2003) argues that effective comments on students' work represent one of the key characteristics of quality teaching. The students may learn faster, and much more effectively, when they have a clearly sense of how well they are doing and what they might need to do in order to improve.

Here is a comment I give to the students on their composition, who like English very much, but she does not work carefully. I comment:

This is a nice piece of writing which describes your experience well. The only real problems with it are the following four types of minor errors.

— missing words or unnecessary additional words;

- unnatural English;

- some of the badly expressed English;

- grammatical errors, such as"I am willing to devote my life to this career so I make a decision: to be a good teacher in the not far future." the sentence should be "...so I have made a decision ... ". 
The feedback helped them to write more effectively, improve the structure of their composition and increase confidence.

\section{Peer feedback}

Learning is conceived as a social practice situated in a specific context where informal learning is more important than formal instruction. Students can often learn more from formal or informal assessment by their peers or themselves (Ramsden, 2003, p.189). It can help to reduce the assessment tasks of staff, and make a valuable contribution to their learning.

For some exercises in the textbook, I ask the students to offer feedback to each other, from which they can review and improve their learning.

\section{Summative Feedback}

As for summative feedback, it stresses the result of the teaching at the end of the programme or a unit when it is completed. It is just as Sadler (1998) said: "Summative contrasts with formative assessment in that it is concerned with summing up or summarizing the achievement status of a student, and is geared towards reporting at the end of a course of study especially for purposes of certification. It is essentially passive and do not normally have immediate impact on learning...."

It is to see how well students have learned what they were supposed to have learned. The grade is final. The final grade is often the sum of separate ratings. It is helpful to give students feedback on how well they are doing on component aspects of a course. For instance, in the middle examination, the student got 85 marks, namely, he has learned the content before the mid-exam well. He masters the main points of these parts.

\section{The mid-term and the final exams}

The school gives these exams. The summative feedback usually includes several parts:

\section{Percentage of final}

$\begin{array}{lc}\text { Mid-exam } 2 \text { hours } & 20 \% \\ \text { Final 2-hour exam } & 50 \% \\ \text { Spoken English exam } & 20 \% \\ \text { Homework } & 10 \%\end{array}$

The result of the final summative feedback is the most important feedback that students get. Summative feedback provided by me is too limited, and I think it is important to be positive, even when the grade is low I want try to balance the other parts to encourage the students if the students work very hard.

I hope I can find out a better way to give a feedback that can ensure our students would benefit from it.

\section{Some thoughts on feedback}

Feedback is a social process that may be interpreted in different ways. Some students may view oral comments as feedback, but some students may consider this form of feedback _ written comments. I made a question to do a survey, which asked students to identify barriers to effective feedback, revealed feedback that they lack of feedback or lack of follow-up was a key problem. For example:

1) Few comments on the feedback are given. Feedback seems like a means of giving a grade rather than helping me to learn.

2) Lack of follow- up guidelines to correct mistakes made.

3) I am interested in my mark and grade only. I use it to see how well I've done, especially compared to others.

I give them some detailed comments on some of the compositions, but I have not enough time to provide more detailed feedback on most of assignments for such large class sizes. Students complained they rarely received any feedback on examinations other than grade. Maybe I thought it was the institutional phenomenon, the university wants to keep the examination paper. Although students want to learn from feedback, they often found this difficult. Anyway, teachers who provide feedback should focus on formative feedback and link to deep learning and make reflection and independent learners increased emphasis on feedback.

\section{Summary}

The teacher should provide constructive feedback, which is positive and gives some powerful piece of advice comprising not just commentary about what has been done, but suggestions for what can be done next. An understanding feedback can lead to the design of opportunities for students to make mistakes and advance their understanding through making these mistakes. 
The formative feedbacks that I provide are sometimes limited, as an example, just comments for composition is not clear enough for students to understand. I feel that is strength, which I have written some comments; I encourage the students by providing positive comments or constructive criticism. Nevertheless, it took me much time to assess the composition and write feedback because my experience in higher education is not rich. So I should give more detail and clear feedback to them. I will try to printed feedback for students to consult it later. I will use e-mail feedback for them to read again later, even file it.

The summative feedback is usually a form of scores; the students are only interested in the mark. I think I should try to give students detailed and developmental feedback to let the students evaluate and examine themselves correctly and timely, which can stimulate their learning interest. The proper feedback can give students the confidence and encouragement to carry out their further learning. I want to find some more kinds of feedback the students like. I want to generalize some practical feedback to students with specifying the relevant purposes encourage the students' deep approaches to learning.

\section{References}

Askew, S and lodge, C. (2000). Gifts, ping-pong and loops-linking feedback and learning. In S. Askew(ed) Feedback for Learnin. London: RoutledgeFalmer, pp1-17.

Biggs, J. (2003). Teaching for quality learning at University. Second edition. Buckingham: The Society for Research into Higher Education \& Open University Press. p141; pp39-41.

Brown, S \& Knight, P. (1994). Assessing learners in higher education. London: Kogan Page. P99.

Higgins, R., Hartley, P. and Skelton, A. (2002). The conscientious consumer: reconsidering the role of assessment feedback in student learning. Studies in Higher Education. 27 (1), pp.53 - 64.

Orrell, J. (2006). Feedback on learning achievement: rhetoric and reality. Teaching in Higher Education Vol. 11, No. 4, October 2006, pp. 441-456.

Race, P. (1998; 2007). The Lecturer's Toolkit, $3^{\text {rd }}$ ed. London: Routledge. pp192-204.

Race, P. (2001) Using feedback to help students learn. [Online]Available at: www.heacademy.ac.uk/resources/detail/id432-using-feedback accessed August 2007.

Ramsden, P. (2003). Learning to teach in higher education. 2ed. London: RoutledgeFalmer. p.88 ; p.187; p.189.

Sadler, D R. (1998). Formative Assessment and the design of Instructional Systems. Instructional Science 18, $119-144$.

Sally Brown. (2007). Feedback \& Feed-forward. Center for Bioscience Bullent, No.22 Autumn $2007 . \quad$ [Online] Available at: www.bioscience.heacadecy.ac.uk. 